\title{
Effects of an extinguished fear stimulus on avoidance behavior
}

\author{
DENNIS K. KAMANO, Galesburg State Research Hospital, \\ Galesburg, Ill. 61401
}

Rats trained on a Sidman avoidance schedule subsequently received Pavlovian fear conditioning (CS+ paired with electric shock). When the CSt was presented during performance on the avotdance schedule, response rate increased. However, by virtue of repeated extinction sessions, this CS+ gradually lost its excitatory function and indeed gradually came to reduce the rate of avoidance to a level below the baseline. This phenomenon was interpreted as evidence for Pavlovian extinctive inhibition, i.e., the extinguished CS+ functioned as an inhibitor with the capacity to suppress avoidance behavior.

When a stimulus (CS+) which has been consistently paired with an aversive US (Pavlovian fear conditioning) is presented during avoidance performance the avoidance response rate is enhanced. For example, Grossen \& Bolles (1968) with rats, and Rescorla \& LoLordo (1965) with dogs have shown that the presentation of a CS+ increased the rate of responding on a Sidman avoidance schedule.

The present study is concerned primarily with a question surrounding the extinction of the CS+ effect. If the excitatory power of CS+ is reduced through extinction (CS+ consistently unpaired with US), what will be the effects of the extinguished CS+ on avoidance behavior? According to the Pavlovian notion of extinctive inhibition (see Rescorla \& Solomon, 1967), the extinction process "does not merely reduce the excitatory power of CS+ but rather builds up its inhibitory power [p. 171]." Therefore, the extinguished CS+ should attain the status of an inhibitor with the capacity to suppress conditioned avoidance behavior. The present study is an attempt to demonstrate the phenomenon of Pavlovian extinctive inhibition.

\section{SUBJECTS}

The Ss were three 65-day-old, male Wistar albino rats from the colony maintained at the Galesburg State Research Hospital and were housed in individual cages throughout the experiment.

\section{APPARATUS}

The apparatus was a modified Mowrer-Miller shuttlebox of unpainted plywood with the bottom 7 in. of the front side as Plexiglas window, and a grid floor consisting of $1 / 8$-in. brass rods with their centers set 5/16 in. apart. Each compartment measured $9 \times 9 \times 20.5 \mathrm{in}$. and was separated by a hurdle 4 in. high the top of which was lined with two parallel stainless steel strips, and by a drop gate which, when lowered, prevented crossing. A $10 \mathrm{~W}$ light bulb mounted above each compartment permitted a light CS. Shock was delivered to the grid floor and hurdle top by a stimulator which consisted mainly of a power transformer that delivered a $260 \mathrm{Vac}$ on the secondary, two fixed resistors wired in parallel with a total width of 218,000 resistance ohms, and a variable $250,000-0 h m$ potentiometer calibrated in $\mu \mathrm{A}$ within the range of 25 to $450 \mu \mathrm{A}$.

\section{PROCEDURE}

The procedure used was modeled after that described elsewhere (Rescorla, 1967; Rescorla \& LoLordo, 1965).

Avoidance Training

After an initial 10-min adaptation period in the apparatus each $S$ received shuttlebox avoidance training on a Sidman avoidance schedule with shock-shock interval of $5 \mathrm{sec}$ and response-shock interval of $30 \mathrm{sec}$. Shock duration was $.25 \mathrm{sec}$ at $350 \mu \mathrm{A}$. Each $\mathrm{S}$ received one $30-\mathrm{min}$ avoidance training session per day until performance had stabilized to not less than 100 avoidance responses and no more than seven shocks per session over five consecutive days. Three out of five Ss met the avoidance criterion within 12 sessions, and the other two were discarded for failing to meet the criterion.

Pavlovian Conditioning

After reaching the avoidance training criterion, $S$ was confined to half of the shuttlebox and given Pavlovian fear conditioning followed by avoidance training on alternate days. The conditioning sessions (days) were presented alternately on the two sides of the shuttlebox, and each session consisted of 12 trials with a mean intertrial interval of $1.5 \mathrm{~min}$ (range, 1-2 min). Twelve light CSs (four each) of 10,20, or $30 \mathrm{sec}$ duration coterminous with a standard 5 -sec, $350 \mu \mathrm{A}$ shock were randomly distributed in each session. Pavlovian conditioning and avoidance training days were alternated for a total of four Pavlovian and four avoidance days.

Test for Excitation

The alternating sequence was followed by a test session in which S performed the avoidance response without shock (i.e., under extinction conditions). The 30-min test session consisted of six 5-min segments, and the 30-sec CS+ was presented on the fourth minute of every 5 -min segment. The number of avoidance responses in successive 30-sec periods preceding, during, and following $\mathrm{CS}+$ presentation were recorded.

Test for Extinctive Inhibition

The test session for CS+ was then followed in sequence by an avoidance training day, a Pavlovian extinction day (CS+ unpaired with shock), and a test day comprising a three-day series. That is, the avoidance and extinction days were always followed by a test day. This three-day series was repeated a total of six times. These 30-min test sessions were identical to the initial session except that $S$ received a shock if it failed to respond within $30 \mathrm{sec}$ after the post-CS period. Such a shock was sufficient to reactivate avoidance responding, and after four consecutive avoidance responses the 5-min test segment with shock contingencies off was reinstated. The need for shock, however, was rare with Ss 72 and 74 each receiving only a total of two shocks, and S 70 three shocks over the six test sessions. As before, the number of avoidance responses in successive 30-sec periods preceding, during, and following CS presentation were recorded for each of the six-test sessions.

Pavlovian Re-conditioning

Finally, a three-day series involving an avoidance training day, a Pavlovian fear conditioning day, and a test day was repeated twice, and the number of avoidance responses for each of the two-test sessions was recorded as before.

$$
\text { RESULTS AND DISCUSSION }
$$

The baseline response rate (i.e., the rate of response during the 30-sec periods immediately preceding the onset of the CS) was used to evaluate the excitatory and inhibitory effects of the CS.

The number of avoidance responses of each $\mathrm{S}$ during 30-sec periods before, during and following CS+ presentation on the initial-test session are shown in the left hand side of Fig. 1. It is clear that the effect of CS+ was to enhance the avoidance response rate, which confirmed the findings of previous studies (e.g., Grossen \& Bolles, 1968; Rescorla \& LoLordo, 1965). Also noteworthy was the drop in avoidance responding during the 30-sec periods following CS+ presentation. Evidently, CS+ offset which, in this study, consistently signalled a no-shock period during conditioning acquired an inhibitory function. 

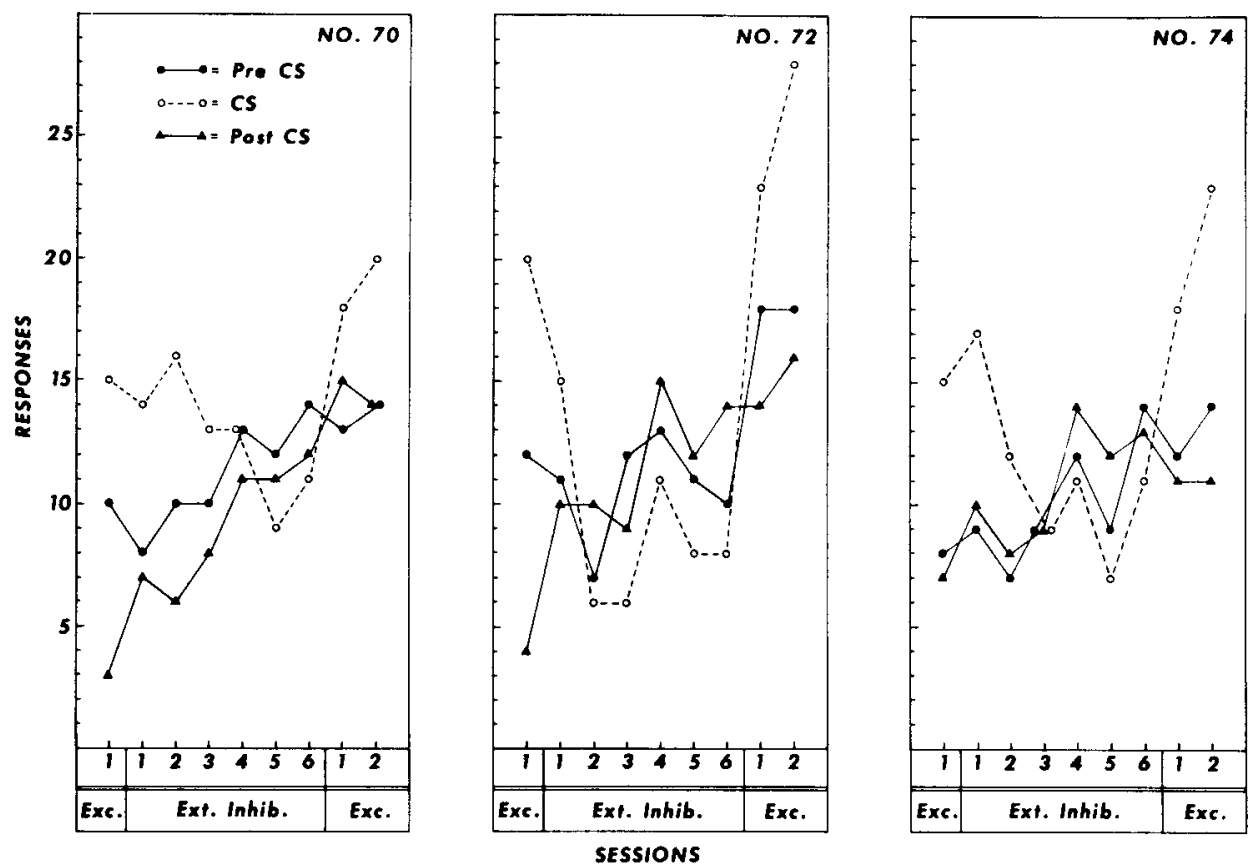

Fig. 1. Number of responses of each $S$ during 30 -sec periods before, during, and following CS presentation in test of excitation and extinctive inhibition sessions. (Each point represents the sum of responses over six 30 -sec periods per session.)

The number of avoidance responses of each $\mathrm{S}$ during $30-\mathrm{sec}$ periods before, during and following CS presentation on the test sessions for extinctive inhibition are shown in Fig. 1. It can be seen that the CS+ by virtue of repeated extinction sessions gradually lost its excitatory function and eventually reduced the rate of avoidance to a level below baseline. This suppression of avoidance relative to the base rate was interpreted as evidence of Pavlovian extinctive inhibition. The inhibitory property of the extinguished CS+ could also be inferred from the recovery of avoidance response rate during the post-CS period

The right hand side of Fig. 1 reveals the effect of once again pairing the extinguished CS+ with shock. As can be seen the excitatory power of CS+ was readily reinstated by re-conditioning, thus demonstrating the consistency with which the excitatory property of CS+ could be produced by the present experimental procedure.

In summary, a CS+ established through classical conditioning acquired an excitatory function with the capacity to increase avoidance response rate. On the other hand when the excitatory properties of the CSt were reduced through extinction training, the extinguished CS+ acquired an inhibitory function with the capacity to reduce the rate of avoidance responding. The data are entirely consistent with, and provide an experimental demonstration of, the Pavlovian notion of extinctive inhibition.

\section{REFERENCES}

GROSSEN, N. E., \& BOLLES, R. C. Effects of a classical conditioned 'fear signal' and 'safety signal' on nondiscriminated avoidance behavior. Psy chonomic Science, 1968, 11, 321-322.

RESCORLA, R. A. Inhibition of delay in Pavlovian fear conditioning. Journal of Comparative \& Physiological Psychology, 1967, 64, 114-120.

RESCORLA, R. A., \& LoLORDO, V. M. Inhibition of avoidance behavior. Journal of Comparative \& Physiological Psychology, 1965, 59,406412 .

RESCORLA, R. A., \& SOLOMON, R. L. Two-process learning theory: Relationships between Pavlovian conditioning and instrumental learning. Psychological Review, 1967, 74, 151-182. 